\title{
Zero One Sampling System
}

\author{
Arumainayagam S.D ${ }^{1}$, Vennila $\mathrm{J}^{2}$ \\ Department of Statistics ${ }^{l}$ \\ Government Arts College, \\ Coimbatore - 641 018, \\ Tamil Nadu, India. \\ Email:devarajs567@gmail.com ${ }^{1}$ \\ Department of Statistics ${ }^{2}$ \\ KMCH College of Pharmacy, \\ Coimbatore - 641048 , \\ Tamil Nadu, India \\ Email: nilajagan92@gmail.com
}

\begin{abstract}
This paper introduces a new switching system meant for costly and destructive testing. Measures of performance, designing of system for various entry parameters and comparison with existing plans are given.
\end{abstract}

Index Terms- Acceptance Sampling System, Quick Switching System, Destructive Testing.

\section{INTRODUCTION}

Dodge (1967) introduced a new sampling system called "Quick Switching System” (QSS-1) for attributes acceptance sampling plan, involving both normal and tightened plans. The application of the system is as follows:

1. Adopt a pair of sampling plans, a normal plan $(\mathrm{N})$ and tightened plan $(\mathrm{T})$, the plan $\mathrm{T}$ to be tightened OC curve wise than plan $\mathrm{N}$.

2. Use plan $\mathrm{N}$ for the first lot (optional): can start with plan $\mathrm{T}$; the OC curve properties are the same; but first lot protection is greater if plan $\mathrm{T}$ is used.

3. For each lot inspected; if the lot is accepted, use plan $\mathrm{N}$ for the next lot and if the lot is rejected, use plan $\mathrm{T}$ for the next lot'.

Further, Romboski (1969) has developed two QSSs, namely QSS $\left(\mathrm{n}, \mathrm{c}_{\mathrm{N}}, \mathrm{c}_{\mathrm{T}}\right)$ and QSS $\left(\mathrm{n}, \mathrm{kn}, \mathrm{c}_{0}\right)$. Soundararajan and Arumainayagam (1988) provided the tables for the selection of modified QSS. Soundararajan and Arumainayagam (1990, 1991, 1992, 1994 and 1995) have developed QSS using single, double and repetitive sampling plans as reference plans. Soundararajan and Arumainayagam (1992) developed systems based on QSS for products involving costly and destructive testing. Suresh (1993) has proposed a procedure for selection of QSS indexed through various quality limits.

Arumainayagam and Uma (2008) constructed the tables for matched single, double and multiple sampling plans using QSS. Suresh and Kaviyarsu(2008) studied quick switching system with conditional group sampling plan as reference plan.
Arumainayagam and Uma (2009 and 2013) have developed QSS using single sampling plan as

reference plan with weighted Poison distribution Suresh and Jayalakshmi (2009) have developed QSS with special type of double sampling plan as reference plan.

Arumainayagam and Uma (2011) have studied QSS using triple sampling plan as reference plan. Uma and Nandhinidevi (2015) have studied the quick switching system with fuzzy logic system in Poisson distribution. Uma and Gunasekaran (2016) have developed QSS Zero Inflated Poisson Distribution as reference plan and compared ZIP with Poisson distribution for the purpose of consumer protection. Uma and Ramya (2017) studied QSS with double sampling plan fuzzy binomial distribution as the baseline distribution. Divya and Arumainayagam (2018) studied QSS using multiple sampling plans as reference plan.

This paper introduces a new sampling inspection system meant for costly and destructive testing based on the switching rules of QSS. This system employs double sampling plan with $\mathrm{o}$ and 1 as acceptance numbers for normal plan while the tightened plan uses single sampling plan with zero acceptance numbers. When the lot contains costly and destructive items and when the quality is good, DSP $(0,1)$ plan is employed to give some advantage to the producers. However, when a lot is rejected, then SSP with zero acceptance number is employed to eliminate the lots with defective items thus giving protection to the consumer. 


\section{Available online at www.ijrat.org}

\section{ZERO ONE SAMPLING SYSTEM}

This system is designated as zero one sampling system ZOSS $(\mathrm{n} ; \mathrm{k})$, where the normal double sampling has the parameters of $n_{1}=n_{2}=n, c_{1}=0$ and $c_{2}=1$ and tightened single sampling has the parameters $\mathrm{kn}, \mathrm{k} \geq 1$.

\subsection{Conditions for Application}

i. The product to be inspected is of a series of successive lots produced by a continuing process. ii. Normally, lots are expected to be essentially of the same quality.

iii. Lots are submitted substantially in the order of production.

iv. Inspection is by attributes, with quality defined as the fraction non-conforming.

\subsection{Operating Procedure}

Step 1: From a lot, take a random sample of size $n$ and count the number of defectives $\mathrm{x}_{1}$.

(i) If $x_{1}=0$, then accept the lot, repeat step 1 for the next lot.

(ii) If $x_{1}>1$, then reject the lot and continue step 2 for the next lot.

(iii) If $\mathrm{x}_{1}=1$, then take a second random sample of size $\mathrm{n}$ form the same lot, and count the number of defectives $x_{2}$.

(iv) $\mathrm{x}_{1}+\mathrm{x}_{2}=1$, then accept the lot and repeat step 1 for the next lot

(v) $\mathrm{x}_{1}+\mathrm{x}_{2}>1$, then reject the lot and go to step 2 for the next lot.

Step 2: From the next lot, take a random sample of size $\mathrm{kn}$ at tightened inspection level and count the number of defectives $\mathrm{x}$.

(i) If $x \leq 0$, accept the lot and go to step 1 for the next lot.

(ii) If $x>0$, reject the lot and repeat step 2 for the next lot.

\section{MEASURES OF PERFORMANCE}

The OC function of ZOSS ( $\mathrm{n}$; $\mathrm{k}$ ) is given below

$$
P_{a}(p)=\frac{P_{T}}{1-P_{N}+P_{T}}
$$

Where

$\mathrm{P}_{\mathrm{N}}=$ Proportion of lots expected to be accepted when using normal double sampling plan

$\mathrm{P}_{\mathrm{T}}=$ Proportion of lots expected to be accepted when using tightened single sampling plan

Under the assumption of Poisson Model (Hamaker and Van Strik (1995)), values of $\mathrm{P}_{\mathrm{N}}$ and $\mathrm{P}_{\mathrm{T}}$ are given by

$$
\begin{aligned}
& P_{N}=e^{-(n p)}+n p e^{-(2 n p)} \\
& P_{\boldsymbol{T}}=e^{-k n p}
\end{aligned}
$$

\subsection{Properties of the OC Curve}

1. Figures. 1 and 2 give the normal, tightened and composite OC curve of ZOSS. The composite OC curve lies between normal and tightened OC curves. For good quality, the normal plan has more probability being applied in the system and hence it is closer to the composite OC curve. From these curves; it is observed that, when comparing the composite OC curve with its corresponding normal and tightened OC curves, it is in better shape than the other curves.

2. Figures 3 and 4 give a set of composite OC curves. In these curves, the normal plan is fixed and in the tightened plan $\mathrm{k}$ is allowed to increase. That is tightening is made severe. It is observed that as the value of $\mathrm{p}$ increases, the OC curve approaches to the shape of an ideal OC curve.

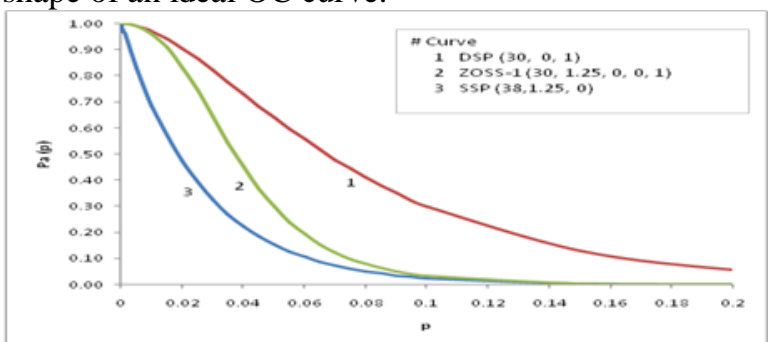

Figure 1: Normal, Tightened and Composite OC curves of ZOSS

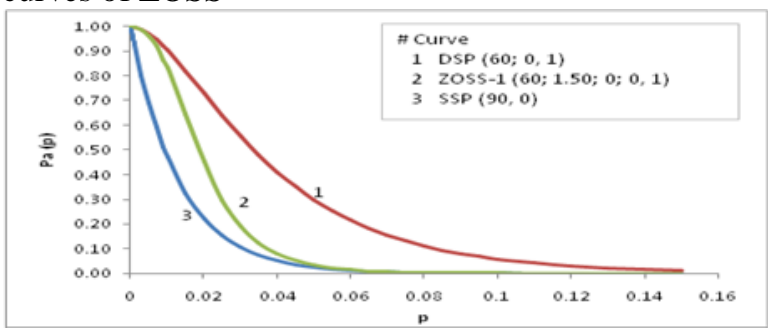

Figure 2: Normal, Tightened and Composite OC curves of ZOSS

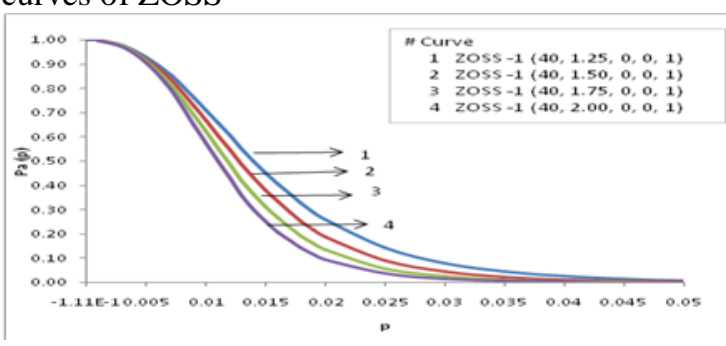

Figure 3: Composite OC curves of ZOSS 


\section{Available online at www.ijrat.org}

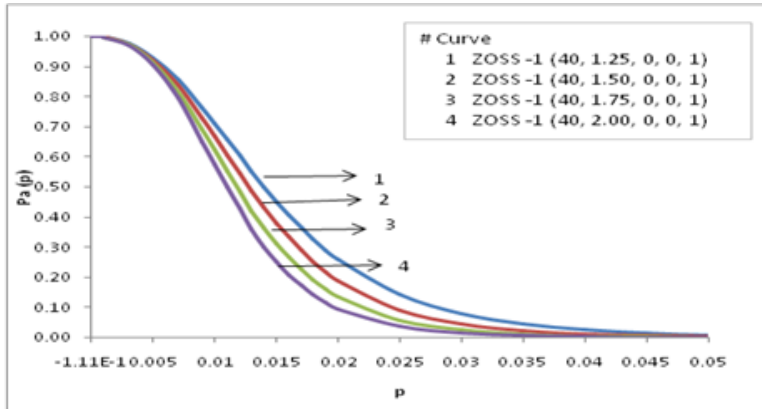

Figure 4: Composite OC curves of ZOSS

\section{ASN}

Based on the work of Stephens and Larson (1967), the ASN function for the ZOSS is given below

$\mathrm{ASN}=\mathrm{ASN}_{\mathrm{N}} \mathrm{P}^{\mathrm{N}}+\mathrm{ASN}_{\mathrm{T}} \mathrm{P}^{\mathrm{T}}$

Where

$\mathrm{ASN}_{\mathrm{N}}=\mathrm{ASN}$ of Normal double sampling plan $\mathrm{ASN}_{\mathrm{T}}=\mathrm{ASN}$ of Tightened single sampling plan $\mathrm{P}^{\mathrm{N}} \quad=$ the expected proportions of lots inspected during normal inspection

$\mathrm{P}^{\mathrm{T}} \quad=$ the expected proportions of lots inspected during tightened inspection

The ASNs of the normal double and tightened single sampling plans of ZOSS (n, k) are given by

$$
\begin{array}{ll}
A S N_{N}=n+n\left(1-\left(e^{-n p}+n p e^{-2 n p}\right)\right) & \\
\mathrm{ASN}_{\mathrm{T}}=\mathrm{n} & \text { and } \\
\mathrm{P}^{\mathrm{N}}=e^{-n p}+n p e^{-2 n p} & \\
\mathrm{P}^{\mathrm{T}}=1-e^{-n p} &
\end{array}
$$

On substituting equations (4) and (5) into equation (3), we get the ASN of ZOSS (n, k) as

$$
\begin{aligned}
A S N(p)=n e^{-n p}\left[1+2 n p e^{-n p}\right. & \left.+e^{-n p}+(n p)^{2} e^{-2 n p}\right] \\
& +k n\left[1-e^{-k n p}\right]
\end{aligned}
$$

The average total inspection of ZOSS $(n ; k)$ is given by

$$
I=A T I_{N} P^{N}+A T I_{T} P^{T}
$$

Where $\mathrm{ATI}_{\mathrm{N}}$ and $\mathrm{ATI}_{\mathrm{T}}$ are the average total inspection of the normal double sampling plan and tightened single sampling plan respectively. From Duncan (1986), $\mathrm{ATI}_{\mathrm{N}}$ and $\mathrm{ATI}_{\mathrm{T}}$ for ZOSS (n; k) under Poisson model are given by

$$
\begin{aligned}
& A T I_{N}=n+n\left(1-P_{a}\right)+(N-n)\left(1-P_{1}\right) \\
& A T I_{T}=n+\left(1-P_{a}\right)(N-n)
\end{aligned}
$$

Where $\mathrm{N}$ is the lot size and substituting equations (5), (8) and (9) into equations (7), we get the ATI of ZOSS $(\mathrm{n}, \mathrm{k})$ as given below

$$
\begin{gathered}
I=2 n+\left\lfloor 1-e^{-n p}+n p e^{-2 n p}\right\rfloor(N-n)\left\lfloor e^{-n p}+n p e^{-2 n p}\right\rfloor \\
+N\left[1-e^{-k n p}\right]
\end{gathered}
$$$$
\text { 5. AOQ VALUE }
$$

Assuming the nonconforming units are replaced by good units in samples taken from accepted lots and also that nonconforming units are completely replaced in rejected lots, the average outgoing quality of ZOSS is given by

$$
\begin{aligned}
& A O Q=p\left(\frac{N-I}{N}\right) \\
& =p \cdot P_{a}(p) \text { when } n / N \text { is Small } \\
& \text { Also, } A O Q L=p_{m} . P_{a}\left(p_{m}\right)
\end{aligned}
$$

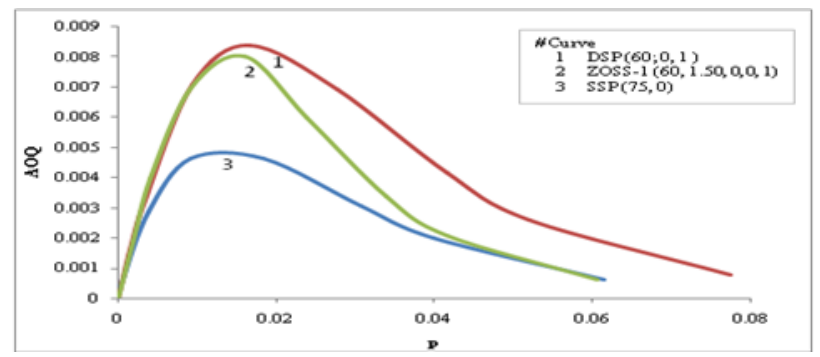

Figure 5: Average Outgoing Quality Curves of Normal SSP, Tightened DSP and ZOSS

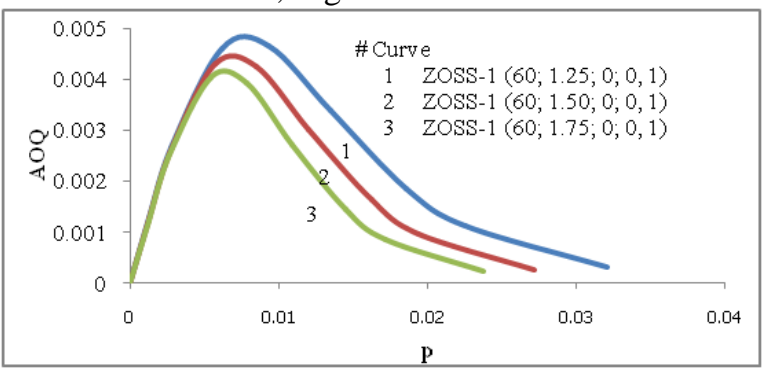

Figure 6: Average Outgoing Quality Curves of Normal SSP, Tightened DSP and ZOSS

From the above AOQ curve,

1. Figure 5 gives the average outgoing quality curve of ZOSS using equation (12) and its normal single sampling and tightened double sampling plans. The AOQ curve of the system lies between those of normal single sampling plan and tightened double sampling plan. In this curves can observed that the small values of $p$, the outgoing quality of the system lies between those of the normal single sampling and tightened double sampling plans.

2. Figure 6 gives a set of AOQ curves of ZOSS (n, k). In this curve, it is observed that, for good quality the outgoing quality resulting from the three systems are same whereas for poor quality, as the tightening become severe, the outgoing quality $\mathrm{p}$ decreases. 


\section{Available online at www.ijrat.org}

\section{DESIGNING SYSTEM}

\subsection{Plotting the OC Curve}

Table 1 can be used to obtain the values of $\mathrm{p}$ and $\mathrm{Pa}(\mathrm{p})$ to plot the OC curve of a given ZOSS (n, k).

Example

For ZOSS $n=50, k=1.50 \mathrm{c}=0 ; \mathrm{c}_{1}=0 \mathrm{c}_{2}=1$, division of entries opposite to $c=0, c_{1}=0$ and $c_{2}=1$ row of in Table 1 by 50 leads to the following Table:

Table 1 - Values for OC curve of ZOSS $(50,1.50$, $\mathbf{0 , 0 , 1 )}$

\begin{tabular}{|c|c|c|c|c|c|c|c|c|}
\hline $\begin{array}{c}\mathrm{Pa}( \\
\mathrm{p})\end{array}$ & 0.99 & 0.95 & 0.75 & 0.50 & 0.25 & 0.10 & 0.05 & 0.01 \\
\hline $\mathrm{p}$ & $\begin{array}{c}0.00 \\
16\end{array}$ & $\begin{array}{c}0.00 \\
36\end{array}$ & $\begin{array}{c}0.00 \\
88\end{array}$ & $\begin{array}{c}0.01 \\
43\end{array}$ & $\begin{array}{c}0.02 \\
25\end{array}$ & $\begin{array}{c}0.03 \\
31\end{array}$ & $\begin{array}{c}0.04 \\
15\end{array}$ & $\begin{array}{c}0.06 \\
20\end{array}$ \\
\hline
\end{tabular}

\subsection{Designing the Systems, Given $p_{1}, p_{2}, \alpha$ and $\beta$} Table 4 can be used to design ZOSS (n; k) for given $\mathrm{p}_{1}, \mathrm{p}_{2}, \alpha$ and $\beta$ by the following steps:

1 . Find the value of $\mathrm{p}_{2} / \mathrm{p}_{1}$.

2. Determine the value of $p_{2} / p_{1}$ in Table 4 in the column for appropriate $\alpha$ and $\beta$ that is closer to the computed $\mathrm{p}_{2} / \mathrm{p}_{1}$.

3 . Find the values of $\mathrm{k}$ corresponding to the ratio located.

4. Corresponding to the selected $\mathrm{k}$, from Table 3, find the value of $\mathrm{np}_{1}$

5. The sample size of the system is found by dividing $\mathrm{np}_{1}$ by $\mathrm{p}_{1}$

Example:

To obtain ZOSS $(n ; k)$ for the given values of $\mathrm{p}_{1}=$ $0.01, \alpha=0.05, \mathrm{p}_{2}=0.09$ and $\beta=0.10$, the following steps are to be followed:

1. Compute $\mathrm{p}_{2} / \mathrm{p}_{1}=0.09 / 0.01=9.00$

2. The value of $p_{2} / p_{1}$ which is nearly equal to 9.00 in

Table 4 under the column of $\alpha=0.05$ and $\beta=0.10$ is 9.0922

3. The value of $\mathrm{k}$ corresponding to 4.5083 are $\mathrm{k}=$ 1.50 .

4. For $\mathrm{k}=1.50$, value of $\mathrm{np}_{1}$ obtained from Table 3 is 0.1823 .

5. The sample size is determined as $n=n p_{1} / p_{1}=$ $0.1823 / 0.01=18$.

6. The designed system is ZOSS - $1(18 ; 1.50 ; 0 ; 0,1)$.

\subsection{Designing system given $A Q L$ and $A O Q L$}

Table 5 can be used to design ZOSS (n; k) for specified values of AQL and AOQL.

\section{Example}

To determine a ZOSS $(\mathrm{n} ; \mathrm{k})$, having AQL $(\alpha=0.05)=$ 0.01 and $\mathrm{AOQL}=0.0006$, compute $\mathrm{AOQL} / \mathrm{p}_{1}=$ $0.0006 / 0.01=0.06$. From Table 5 , under the column headed $\mathrm{AOQL} / \mathrm{p}_{1}$, value closer to the desired value is 0.0605 , which corresponds to a value of $\mathrm{k}=1.65$. Corresponding to these parameters, value of $\mathrm{np}_{1}$ obtained from Table 5 is 0.1799 . The normal double sampling plan sample size is obtained by $\mathrm{n}=\mathrm{np}_{1} / \mathrm{p}_{1}=$ $0.1799 / 0.01=18$. The designed system is ZOSS $(18$; $1,65 ; 0 ; 0,1)$.

\subsection{Indifference Quality Level and $h_{0}$}

Table 5 can be used to design ZOSS (n; k) indexed by point of control and point of control.

\section{Example}

To design a ZOSS having $\mathrm{p}_{0}=0.02$ and $\mathrm{h}_{0}=1.2$, from Table 5 , under the column headed $\mathrm{h}_{0}$ find the value which is closer to the desired value. The value is 1.2020 which has associated with it a value of $\mathrm{k}=$ $1.65, \mathrm{c}=0, \mathrm{c}_{1}=0$ and $\mathrm{c}_{2}=1$. Corresponding to these parameters, value of $\mathrm{np}_{0}$ is 0.6860 . The sample size of normal double sampling plan is obtained as $\mathrm{n}=\mathrm{np}_{0} / \mathrm{n}$ $=0.6860 / 0.02 \approx 34$. The designed system is ZOSS $(34 ; 1.65,0 ; 0,1)$.

\subsection{Calculating AOQL of the system}

Table 5 provides the $\mathrm{np}_{\mathrm{m}}$ and $\mathrm{nAOQL}$ values for ZOSS (n; k). This table can be used to determine $n p_{m}$ and $\mathrm{nAOQL}$ of a system.

\section{Example:}

Determine the pm and AOQL of ZOSS (34; 1.65; 0 ; 0 , 1). From Table 5 , corresponding to $\mathrm{k}=1.65$, $\mathrm{nAOQL}=$ 0.0109 and $n p_{m}=3.4991$. so AOQL $=\mathrm{nAOQL} / \mathrm{n}=$ $0.0109 / 34=0.0003 \%$ and $\mathrm{p}_{\mathrm{m}}=\mathrm{np}_{\mathrm{m}} / \mathrm{n}=3.4991 / 34$ $=0.10 \%$.

\subsection{Conversion of Parameters}

For ZOSS (n; k), if $\mathrm{p}_{1}=0.02, \mathrm{p}_{2}=0.04, \alpha=0.05$ and $\beta=0.10$, the system satisfying the requirements can be obtained from Table 5 as $\mathrm{n}=34, \mathrm{k}=1.65, \mathrm{c}=0, \mathrm{c}_{1}=0$ and $\mathrm{c}_{2}=1$. Corresponding to $\mathrm{k}=1.65, \mathrm{c}=0, \mathrm{c}_{1}=0$ and $\mathrm{c}_{2}=1$, from Table 3,4 and 5 , one can get the following:

$\mathrm{np}_{1}=0.1799, \mathrm{np}_{\mathrm{m}}=3.4991, \mathrm{nAOQL}=0.0109$

$\mathrm{np}_{0}=0.6860$ and $\mathrm{h}_{0}=1.2020$.

So,AOQL $=\mathrm{nAOQL} / \mathrm{n}=0.0109 / 34=0.0003$ $\mathrm{p}_{0}=\mathrm{np}_{0} / \mathrm{n}=0.1799 / 34=0.0053$.

So, when $\mathrm{p}_{1}=0.02, \alpha=0.05, \mathrm{p}_{2}=0.04$ and $\beta=0.10$, the other similar sets of parameters are given by

1. $\mathrm{p}_{1}=0.02(\alpha=0.05)$ and AOQL $=0.0003$

2. $\mathrm{p}_{0}=0.0053$ and $\mathrm{h}_{0}=1.2020$.

\section{COMPARISON \& CONCLUSION}

Four QSS-1 (n, $\mathrm{k}_{\mathrm{n}}, \mathrm{c}_{0}$ ), QSS-2 (n, $\left.\mathrm{k}_{\mathrm{n}}, \mathrm{c}_{0}\right)$, QSS-3 (n, $\mathrm{k}_{\mathrm{n}}$, $\mathrm{c}_{0}$ ) and their equivalent $\operatorname{ZOSS}(\mathrm{n}, \mathrm{k})$ values are given in Table 2. The measure operating ratio is used as the 


\section{Available online at www.ijrat.org}

basis for 'matching'. QSS-1 ( $\left.\mathrm{n}, \mathrm{k}_{\mathrm{n}}, \mathrm{c}_{0}\right)$, QSS-2 (n, $\mathrm{k}_{\mathrm{n}}$, $\left.\mathrm{c}_{0}\right)$, QSS-3 ( $\left.\mathrm{n}, \mathrm{k}_{\mathrm{n}}, \mathrm{c}_{0}\right)$ plan values are taken from Soundararajan and Arumainayagm (1988). From this table, it is observed that the new system requires lesser sample size and it's shown to be more efficient than the existing one.

\section{CONSTRUCTION OF TABLES}

The OC function of ZOSS (n; k) is given below

$$
P_{a}(p)=\frac{P_{T}}{1-P_{N}+P_{T}}
$$

Where

$$
\begin{aligned}
& P_{N}=e^{-(n p)}+n p e^{-(n p)}\left[e^{-(n p)}\right] \\
& \boldsymbol{P}_{\boldsymbol{T}}=e^{-k n p}
\end{aligned}
$$

For given values of $\mathrm{c}, \mathrm{c}_{1}, \mathrm{c}_{2}$ and $\mathrm{P}_{\mathrm{a}}(\mathrm{p})$, equation (1) is solved for $n p$ using unit value approach technique in MATLAB program. Table 3 provides np values for given $c, c_{1}, c_{2}$ and $P_{a}(p)$. From these values, operating ratio $p_{2} / p_{1}$ is calculated and that values are tabulated in Table 4 for assumed values of $\alpha$ and $\beta$. Assuming $\mathrm{nAOQ}=\mathrm{np} * \mathrm{P}_{\mathrm{a}}(\mathrm{p})$, for given values of $\mathrm{c}, \mathrm{c}_{1}, \mathrm{c}_{2}$, the values of $n p_{m}$ which maximise $n A O Q$ can be obtained from equation (1). Values of $\mathrm{np}_{\mathrm{m}}$ and $\mathrm{nAOQL}$ are tabulated for given $\mathrm{c}, \mathrm{c}_{1}$ and $\mathrm{c}_{2}$ values in Table 5. The values of $A O Q L / p_{1}$ of Table 5, for given values of $c$, $c_{1}$ and $c_{2}$ values are obtained by dividing $n A O Q L$ by $\mathrm{np}_{1}$ for the appropriate $\mathrm{c}, \mathrm{c}_{1}$ and $\mathrm{c}_{2}$ values. Using the $\mathrm{np}_{0}$ values of Table $5, \mathrm{~h}_{0}$ values are calculated and tabulated in Table 5.

\section{REFERENCES}

[1] Arumainayagam SD (1991): "Contributions to the study of Quick Switching System (QSS) and its Applications". Doctoral dissertation, Bharathiar University, Coimbatore, Tamil Nadu, India.

[2] Arumainayagam SD and Divya (2018): "Designing and Selection of Quick Switching Multiple Sampling System - Acceptance Number Tightening", International Journal of Pure and Applied Mathematics, Vol. 119, No. 17, pp. 589602.

[3] Arumainayagam SD and Uma G (2008): Construction of Matched Quick Switching Single Double and Multiple Sampling Systems, International Journal of Statistics and Systems;2008, Vol. 3 Issue 2, p147.

[4] Arumainayagam SD and Uma G (2009): Construction and selection of quick switching multiple sampling system-sample size tightening, Indian Association Productivity and Quality Journal, 2009, vol.34, No.2.

[5] Arumainayagam SD and Uma G (2011): Construction and Selection of Quick Switching Multiple Sampling System - Sample Size Tightening, Quality Control and applied statistics, Vol.56, No.1-2, pp.65-66.
[6] Arumainayagam SD and Uma G (2013): Construction and selection of quick switching system using weighted Poisson distributionsample size tightening, Indian Association Productivity and Quality Journal, 2009, vol.34, No.2.

[7] Arumainayagam SD and Uma G (2009): Construction and Selection of Quick Switching System Using Weighted Poisson Distribution, International Journal of Statistics and Systems;2009, Vol. 4 Issue 2, p127.

[8] Dodge, H. F. (1965): "Evaluation of a Sampling Inspection System having Rules for Switching Between Normal and Tightened Inspection", Technical Report No.14, The Statistics Center, Rutgers - The State University, New Brunswick, New Jersey.

[9] Duncan, A. J. (1986): Quality Control and Industrial Statistics, 5th Edition, Homewood, Illinois, Richard D. Irwin.

[10] Hamaker, H.C. and Van Strik, R. (1955): The Efficiency of Double Sampling for Attributes, Journal of the American Statistical Association, Vol.50, pp. 830-849.

[11] Jayalakshmi, S. (2009): "Contribution to the Selection of Quick Switching System and related sampling plans", Ph.D Thesis, Department of Statistics, Bharathiar University, Coimbatore, Tamil Nadu, India.

[12] Romboski, L. D. (1969): An Investigation of Quick Switching Acceptance Sampling Systems, Ph.D Thesis, Rutgers- The State University, New Brunswick, New Jersey.

[13] Soundararajan V and Arumainayagam SD (1989): "An Extension of Some Switching Procedures Used in Sampling Inspection", International Journal of Quality and Reliability Management, Vol.06 (5) pp.141-153.

[14] Soundararajan V and Arumainayagam SD (1990): "Construction and Selection of Modified Quick Switching System”, Journal of Applied Statistics. Vol.17 (1), pp. 83-114.

[15] Soundararajan V and Arumainayagam SD (1990a): A Generalized procedure for Selection of Attribute Double Sampling plan, Communication in Statistics-Simulation and Computation, Vol.19, No.3, pp.1015-1034.

[16] Soundararajan V and Arumainayagam SD (1990b): Construction and Selection of Modified Quick Switching System, Journal of Applied Statistics, Vol.17, No.1, pp.83-114.

[17] Soundararajan V and Arumainayagam SD (1992): Conditional double sampling system Communications in Statistics - Theory and Methods. 21: 2019-2044.

[18] Soundararajan V and Arumainayagam SD (1992): Quick Switching System for Costly and 


\section{Available online at www.ijrat.org}

Destructive Testing, Sankaya, Series B-Part I, Vol.54, pp.1-12.

[19] Soundararajan V and Arumainayagam SD (1992): Some sampling plans with identical operating characteristic curves Journal of Applied Statistics. 19: 141-153.

[20] Soundararajan V and Arumainayagam SD (1994): Construction and selection of quick switching double sampling system-acceptance number tightening Communication in Statistics Theory and Methods 23, 7 2079-2100.

[21] Soundararajan V and Arumainayagam SD (1995): Construction and evaluation of matched quick switching systems International Journal of Applied Statistics vol.22, no.2, pp. 245-251.

[22] Soundararajan V and Arumainayagam SD (1995): Construction and Selection of quick switching system sample size tightening, Journal of applied Statistics, Vol.22, No.2, 1995, pp. 105119.

[23] Soundararajan V and Arumainayagam SD (1995): Quick switching double sampling system indexed by the crossover point Communications in Statistics - Simulation and Computation. 24: 765-773.

[24] Stephens, K. S. and Larson, K. E. (1967): An evaluation of the MILSTD- 105D Systems of Sampling Plans, Industrial Quality Control, Vol.23, N0.7, pp.310-319.

[25] Suresh, K. K. (1993): A Study on Acceptance Sampling using Acceptable and Limiting Quality Levels, Ph.D., thesis, Department of Statistics, Bharathiar University Coimbatore, Tamilnadu, India.

[26] Suresh, K. K. and Kaviyarasu, V. (2013): Contribution of the Study on Quick Switching System Through Incoming and Outgoing Quality Levels, Ph.D Thesis, Department of Statistics, Bharathiar University, Coimbatore, Tamil Nadu, India.

[27] Uma G and Gunasekaran K (2016): "The Construction and Selection of Quick Switching System Using Zero - Inflated Poisson distribution", International Journal of Advanced Engineering and Global Technology I Vol-04, Issue-02, pp.

[28] Uma G and Ramya K (2017): "Determination of Quick Switching Double Sampling System by Attributes under Fuzzy Binomial Distribution Sample Size Tightening", ICTACT Journal on Soft Computing, Vol 08, ISS. 01, pp.1539-1543

[29] Vennila J and Arumainayagam SD (2017), "Construction and Selection of Quick Switching Single Double Sampling System", International Journal of Applied Mathematics and Statistics, Vol. 56 (6), pp. 124 - 137.
[30] Vennila J and Arumainayagam SD (2018). "Quick Switching System with Different Reference Plans", American Journal of Applied Mathematics and Statistics, Vol. 6, No. 4, 2018 , pp 141-148. 
International Journal of Research in Advent Technology, Vol.7, No.3, March 2019

E-ISSN: 2321-9637

\section{Available online at www.ijrat.org}

Table 3: Values of $n p$ tabulated against $k$ for the given valuesof $P_{a}(p)$ for ZOSS $(n, k)$

\begin{tabular}{|c|c|c|c|c|c|c|c|c|}
\hline $\mathbf{k}$ & 0.99 & 0.95 & 0.75 & 0.50 & 0.25 & 0.10 & 0.05 & 0.01 \\
\hline 1.00 & 0.0828 & 0.1909 & 0.4909 & 0.8603 & 1.4675 & 2.3251 & 3.0032 & 4.6056 \\
\hline 1.10 & 0.0824 & 0.1891 & 0.4790 & 0.8252 & 1.3767 & 2.1420 & 2.7480 & 4.1921 \\
\hline 1.15 & 0.0823 & 0.1882 & 0.4733 & 0.8091 & 1.3366 & 2.0627 & 2.6376 & 4.0128 \\
\hline 1.20 & 0.0821 & 0.1873 & 0.4679 & 0.7939 & 1.2996 & 1.9902 & 2.5369 & 3.8487 \\
\hline 1.25 & 0.0819 & 0.1865 & 0.4626 & 0.7795 & 1.2651 & 1.9235 & 2.4445 & 3.6980 \\
\hline 1.30 & 0.0818 & 0.1856 & 0.4575 & 0.7658 & 1.2331 & 1.8621 & 2.3594 & 3.5592 \\
\hline 1.35 & 0.0816 & 0.1848 & 0.4526 & 0.7528 & 1.2031 & 1.8052 & 2.2808 & 3.4309 \\
\hline 1.40 & 0.0814 & 0.1839 & 0.4478 & 0.7404 & 1.1749 & 1.7524 & 2.2081 & 3.3120 \\
\hline 1.45 & 0.0813 & 0.1831 & 0.4431 & 0.7286 & 1.1485 & 1.7033 & 2.1405 & 3.2015 \\
\hline 1.50 & 0.0811 & 0.1823 & 0.4386 & 0.7172 & 1.1236 & 1.6574 & 2.0775 & 3.0986 \\
\hline 1.55 & 0.0809 & 0.1815 & 0.4342 & 0.7064 & 1.1001 & 1.6144 & 2.0186 & 3.0025 \\
\hline 1.60 & 0.0808 & 0.1807 & 0.4300 & 0.6960 & 1.0778 & 1.5741 & 1.9636 & 2.9126 \\
\hline 1.65 & 0.0806 & 0.1799 & 0.4259 & 0.6860 & 1.0567 & 1.5361 & 1.9119 & 2.8283 \\
\hline 1.70 & 0.0805 & 0.1791 & 0.4218 & 0.6764 & 1.0366 & 1.5004 & 1.8633 & 2.7490 \\
\hline 1.75 & 0.0803 & 0.1784 & 0.4179 & 0.6671 & 1.0175 & 1.4666 & 1.8175 & 2.6745 \\
\hline 1.80 & 0.0802 & 0.1776 & 0.4141 & 0.6583 & 0.9994 & 1.4346 & 1.7743 & 2.6041 \\
\hline 1.85 & 0.0800 & 0.1769 & 0.4104 & 0.6497 & 0.9820 & 1.4043 & 1.7334 & 2.5377 \\
\hline 1.90 & 0.0798 & 0.1761 & 0.4068 & 0.6414 & 0.9654 & 1.3756 & 1.6947 & 2.4749 \\
\hline 1.95 & 0.0797 & 0.1754 & 0.4032 & 0.6334 & 0.9496 & 1.3482 & 1.6580 & 2.4154 \\
\hline 2.00 & 0.0795 & 0.1747 & 0.3998 & 0.6257 & 0.9344 & 1.3222 & 1.6231 & 2.3590 \\
\hline 2.05 & 0.0794 & 0.1740 & 0.3964 & 0.6182 & 0.9198 & 1.2973 & 1.5899 & 2.3054 \\
\hline 2.10 & 0.0792 & 0.1733 & 0.3932 & 0.6110 & 0.9058 & 1.2736 & 1.5582 & 2.2543 \\
\hline 2.15 & 0.0791 & 0.1726 & 0.3899 & 0.6040 & 0.8923 & 1.2509 & 1.5281 & 2.2058 \\
\hline 2.20 & 0.0789 & 0.1719 & 0.3868 & 0.5972 & 0.8793 & 1.2292 & 1.4992 & 2.1594 \\
\hline 2.25 & 0.0788 & 0.1712 & 0.3837 & 0.5906 & 0.8669 & 1.2084 & 1.4717 & 2.1152 \\
\hline 2.30 & 0.0786 & 0.1706 & 0.3807 & 0.5842 & 0.8548 & 1.1884 & 1.4453 & 2.0730 \\
\hline 2.35 & 0.0785 & 0.1699 & 0.3778 & 0.5780 & 0.8432 & 1.1693 & 1.4200 & 2.0326 \\
\hline 2.40 & 0.0783 & 0.1693 & 0.3749 & 0.5720 & 0.8320 & 1.1509 & 1.3957 & 1.9939 \\
\hline 2.45 & 0.0782 & 0.1686 & 0.3721 & 0.5661 & 0.8212 & 1.1331 & 1.3724 & 1.9568 \\
\hline 2.50 & 0.0780 & 0.1680 & 0.3694 & 0.5604 & 0.8107 & 1.1161 & 1.3501 & 1.9212 \\
\hline 2.55 & 0.0779 & 0.1674 & 0.3667 & 0.5549 & 0.8006 & 1.0996 & 1.3285 & 1.8870 \\
\hline 2.60 & 0.0778 & 0.1667 & 0.3640 & 0.5495 & 0.7908 & 1.0838 & 1.3078 & 1.8542 \\
\hline 2.65 & 0.0776 & 0.1661 & 0.3614 & 0.5442 & 0.7813 & 1.0685 & 1.2878 & 1.8226 \\
\hline 2.70 & 0.0775 & 0.1655 & 0.3589 & 0.5391 & 0.7720 & 1.0537 & 1.2685 & 1.7922 \\
\hline 2.75 & 0.0773 & 0.1649 & 0.3564 & 0.5340 & 0.7631 & 1.0394 & 1.2499 & 1.7629 \\
\hline 2.80 & 0.0772 & 0.1643 & 0.3540 & 0.5292 & 0.7544 & 1.0255 & 1.2320 & 1.7347 \\
\hline 2.85 & 0.0770 & 0.1637 & 0.3516 & 0.5244 & 0.7460 & 1.0122 & 1.2146 & 1.7074 \\
\hline 2.90 & 0.0769 & 0.1631 & 0.3492 & 0.5197 & 0.7378 & 0.9992 & 1.1978 & 1.6812 \\
\hline 2.95 & 0.0768 & 0.1625 & 0.3469 & 0.5152 & 0.7298 & 0.9866 & 1.1816 & 1.6558 \\
\hline 3.00 & 0.0766 & 0.1620 & 0.3446 & 0.5107 & 0.7220 & 0.9744 & 1.1659 & 1.6312 \\
\hline
\end{tabular}

Table 4: Values of $p_{2} / p_{1}$ tabulated against $k$ values of $\alpha$ and $\beta$ and values for $\operatorname{ZOSS}(n, k)$

\begin{tabular}{|c|c|c|c|c|c|c|c|c|}
\hline \multirow[b]{2}{*}{ k } & \multicolumn{3}{|c|}{$\mathbf{p}_{2} / \mathbf{p}_{1}$ for } & \multirow[b]{2}{*}{$\begin{array}{l}\mathrm{np}_{1} \text { for } \\
\alpha=0.05\end{array}$} & \multicolumn{3}{|c|}{$\mathbf{p}_{2} / \mathbf{p}_{1}$ for } & \multirow[b]{2}{*}{$\begin{array}{l}\mathrm{np}_{1} \text { for } \\
\alpha=0.10\end{array}$} \\
\hline & $\begin{array}{l}\alpha=0.05 \\
\beta=0.10\end{array}$ & $\begin{array}{l}\alpha=0.05 \\
\beta=0.05\end{array}$ & $\begin{array}{l}\alpha=0.05 \\
\beta=0.01\end{array}$ & & $\begin{array}{c}\alpha=0.01 \\
\beta=0.10\end{array}$ & $\begin{array}{l}\alpha=0.01 \\
\beta=0.05\end{array}$ & $\begin{aligned} \alpha & =0.01 \\
\beta & =0.01\end{aligned}$ & \\
\hline 1.00 & 12.1774 & 15.7289 & 24.1218 & 0.1909 & 28.0850 & 36.2758 & 55.6324 & 0.0828 \\
\hline 1.10 & 11.3269 & 14.5314 & 22.1682 & 0.1891 & 25.9811 & 33.3316 & 50.8484 & 0.0824 \\
\hline 1.15 & 10.9595 & 14.0143 & 21.3207 & 0.1882 & 25.0713 & 32.0596 & 48.7739 & 0.0823 \\
\hline 1.20 & 10.6239 & 13.5424 & 20.5452 & 0.1873 & 24.2395 & 30.8982 & 46.8759 & 0.0821 \\
\hline 1.25 & 10.3161 & 13.1099 & 19.8329 & 0.1865 & 23.4761 & 29.8337 & 45.1330 & 0.0819 \\
\hline 1.30 & 10.0327 & 12.7121 & 19.1766 & 0.1856 & 22.7726 & 28.8544 & 43.5275 & 0.0818 \\
\hline 1.35 & 9.7709 & 12.3452 & 18.5700 & 0.1848 & 22.1221 & 27.9504 & 42.0439 & 0.0816 \\
\hline 1.40 & 9.5282 & 12.0055 & 18.0078 & 0.1839 & 21.5187 & 27.1135 & 40.6691 & 0.0814 \\
\hline 1.45 & 9.3026 & 11.6903 & 17.4853 & 0.1831 & 20.9573 & 26.3363 & 39.3917 & 0.0813 \\
\hline 1.50 & 9.0922 & 11.3968 & 16.9986 & 0.1823 & 20.4334 & 25.6127 & 38.2020 & 0.0811 \\
\hline 1.55 & 8.8956 & 11.1230 & 16.5442 & 0.1815 & 19.9434 & 24.9373 & 37.0913 & 0.0809 \\
\hline 1.60 & 8.7113 & 10.8670 & 16.1190 & 0.1807 & 19.4839 & 24.3052 & 36.0521 & 0.0808 \\
\hline 1.65 & 8.5383 & 10.6269 & 15.7203 & 0.1799 & 19.0520 & 23.7125 & 35.0778 & 0.0806 \\
\hline 1.70 & 8.3754 & 10.4014 & 15.3458 & 0.1791 & 18.6453 & 23.1555 & 34.1627 & 0.0805 \\
\hline 1.75 & 8.2218 & 10.1891 & 14.9933 & 0.1784 & 18.2614 & 22.6311 & 33.3015 & 0.0803 \\
\hline 1.80 & 8.0767 & 9.9890 & 14.6609 & 0.1776 & 17.8985 & 22.1363 & 32.4897 & 0.0802 \\
\hline 1.85 & 7.9393 & 9.7999 & 14.3471 & 0.1769 & 17.5547 & 21.6686 & 31.7231 & 0.0800 \\
\hline 1.90 & 7.8091 & 9.6209 & 14.0503 & 0.1761 & 17.2286 & 21.2260 & 30.9982 & 0.0798 \\
\hline 1.95 & 7.6854 & 9.4513 & 13.7692 & 0.1754 & 16.9188 & 20.8063 & 30.3116 & 0.0797 \\
\hline 2.00 & 7.5679 & 9.2904 & 13.5025 & 0.1747 & 16.6240 & 20.4077 & 29.6604 & 0.0795 \\
\hline 2.05 & 7.4559 & 9.1373 & 13.2493 & 0.1740 & 16.3430 & 20.0287 & 29.0419 & 0.0794 \\
\hline 2.10 & 7.3491 & 8.9917 & 13.0084 & 0.1733 & 16.0750 & 19.6679 & 28.4538 & 0.0792 \\
\hline 2.15 & 7.2471 & 8.8529 & 12.7791 & 0.1726 & 15.8189 & 19.3238 & 27.8939 & 0.0791 \\
\hline 2.20 & 7.1497 & 8.7204 & 12.5604 & 0.1719 & 15.5740 & 18.9954 & 27.3601 & 0.0789 \\
\hline 2.25 & 7.0564 & 8.5938 & 12.3518 & 0.1712 & 15.3394 & 18.6815 & 26.8507 & 0.0788 \\
\hline 2.30 & 6.9671 & 8.4728 & 12.1525 & 0.1706 & 15.1146 & 18.3812 & 26.3641 & 0.0786 \\
\hline 2.35 & 6.8814 & 8.3569 & 11.9618 & 0.1699 & 14.8989 & 18.0936 & 25.8987 & 0.0785 \\
\hline 2.40 & 6.7991 & 8.2458 & 11.7793 & 0.1693 & 14.6917 & 17.8178 & 25.4532 & 0.0783 \\
\hline 2.45 & 6.7200 & 8.1392 & 11.6045 & 0.1686 & 14.4925 & 17.5532 & 25.0263 & 0.0782 \\
\hline 2.50 & 6.6440 & 8.0369 & 11.4367 & 0.1680 & 14.3009 & 17.2990 & 24.6170 & 0.0780 \\
\hline 2.55 & 6.5708 & 7.9385 & 11.2757 & 0.1674 & 14.1163 & 17.0546 & 24.2240 & 0.0779 \\
\hline 2.60 & 6.5003 & 7.8439 & 11.1210 & 0.1667 & 13.9384 & 16.8194 & 23.8465 & 0.0778 \\
\hline 2.65 & 6.4323 & 7.7528 & 10.9723 & 0.1661 & 13.7668 & 16.5929 & 23.4835 & 0.0776 \\
\hline 2.70 & 6.3667 & 7.6650 & 10.8292 & 0.1655 & 13.6012 & 16.3747 & 23.1342 & 0.0775 \\
\hline 2.75 & 6.3034 & 7.5804 & 10.6913 & 0.1649 & 13.4411 & 16.1642 & 22.7979 & 0.0773 \\
\hline 2.80 & 6.2422 & 7.4987 & 10.5585 & 0.1643 & 13.2865 & 15.9610 & 22.4737 & 0.0772 \\
\hline 2.85 & 6.1830 & 7.4199 & 10.4304 & 0.1637 & 13.1368 & 15.7647 & 22.1612 & 0.0770 \\
\hline 2.90 & 6.1258 & 7.3436 & 10.3068 & 0.1631 & 12.9920 & 15.5750 & 21.8595 & 0.0769 \\
\hline 2.95 & 6.0703 & 7.2700 & 10.1874 & 0.1625 & 12.8518 & 15.3916 & 21.5683 & 0.0768 \\
\hline 3.00 & 6.0166 & 7.1987 & 10.0721 & 0.1620 & 12.7158 & 15.2140 & 21.2868 & 0.0766 \\
\hline
\end{tabular}


Available online at www.ijrat.org

Table 5: Parametric values for ZOSS (n, k)

\begin{tabular}{|c|c|c|c|c|c|}
\hline $\mathbf{k}$ & $\mathbf{h}_{\mathbf{0}}$ & $\mathbf{n p}_{\mathbf{m}}$ & $\mathbf{n A O Q \mathbf { L }}$ & $\begin{array}{c}\mathbf{A O Q L} \mathbf{p}_{\mathbf{1}} \\
\mathbf{f o r} \mathbf{0 . 0 5}\end{array}$ & $\mathbf{n p}_{\mathbf{1}}$ \\
\hline 1.00 & 0.99 & 5.7581 & 0.0102 & 0.0535 & 0.1909 \\
\hline 1.10 & 1.03 & 5.2356 & 0.0165 & 0.0873 & 0.1891 \\
\hline 1.15 & 1.05 & 5.0086 & 0.0158 & 0.0839 & 0.1882 \\
\hline 1.20 & 1.07 & 4.8006 & 0.0151 & 0.0807 & 0.1873 \\
\hline 1.25 & 1.08 & 4.6094 & 0.0145 & 0.0778 & 0.1865 \\
\hline 1.30 & 1.10 & 4.4329 & 0.0139 & 0.0751 & 0.1856 \\
\hline 1.35 & 1.11 & 4.2696 & 0.0134 & 0.0725 & 0.1848 \\
\hline 1.40 & 1.13 & 4.1180 & 0.0129 & 0.0702 & 0.1839 \\
\hline 1.45 & 1.15 & 3.9770 & 0.0124 & 0.0680 & 0.1831 \\
\hline 1.50 & 1.16 & 3.8454 & 0.0120 & 0.0659 & 0.1823 \\
\hline 1.55 & 1.17 & 3.7225 & 0.0116 & 0.0640 & 0.1815 \\
\hline 1.60 & 1.19 & 3.6072 & 0.0112 & 0.0622 & 0.1807 \\
\hline 1.65 & 1.20 & 3.4991 & 0.0109 & 0.0605 & 0.1799 \\
\hline 1.70 & 1.22 & 3.3973 & 0.0105 & 0.0588 & 0.1791 \\
\hline 1.75 & 1.23 & 3.3015 & 0.0102 & 0.0573 & 0.1784 \\
\hline 1.80 & 1.24 & 3.2110 & 0.0099 & 0.0558 & 0.1776 \\
\hline 1.85 & 1.25 & 3.1254 & 0.0096 & 0.0545 & 0.1769 \\
\hline 1.90 & 1.27 & 3.0445 & 0.0094 & 0.0531 & 0.1761 \\
\hline 1.95 & 1.28 & 2.9677 & 0.0091 & 0.0519 & 0.1754 \\
\hline 2.00 & 1.29 & 2.8948 & 0.0089 & 0.0507 & 0.1747 \\
\hline 2.05 & 1.30 & 2.8255 & 0.0086 & 0.0495 & 0.1740 \\
\hline 2.10 & 1.31 & 2.7596 & 0.0084 & 0.0484 & 0.1733 \\
\hline 2.15 & 1.32 & 2.6967 & 0.0082 & 0.0474 & 0.1726 \\
\hline
\end{tabular}

\begin{tabular}{|c|c|c|c|c|c|}
\hline $\mathbf{k}$ & $\mathbf{h}_{\mathbf{0}}$ & $\mathbf{n p}_{\mathbf{m}}$ & $\mathbf{n A O Q \mathbf { L }}$ & $\begin{array}{c}\mathbf{A O Q L} / \mathbf{p}_{\mathbf{1}} \\
\mathbf{f o r} \mathbf{0 . 0 5}\end{array}$ & $\mathbf{n p}_{\mathbf{1}}$ \\
\hline 2.20 & 1.33 & 2.6368 & 0.0080 & 0.0464 & 0.1719 \\
\hline 2.25 & 1.34 & 2.5795 & 0.0078 & 0.0454 & 0.1712 \\
\hline 2.30 & 1.35 & 2.5248 & 0.0076 & 0.0445 & 0.1706 \\
\hline 2.35 & 1.37 & 2.4724 & 0.0074 & 0.0436 & 0.1699 \\
\hline 2.40 & 1.38 & 2.4223 & 0.0072 & 0.0427 & 0.1693 \\
\hline 2.45 & 1.39 & 2.3742 & 0.0071 & 0.0419 & 0.1686 \\
\hline 2.50 & 1.39 & 2.3281 & 0.0069 & 0.0411 & 0.1680 \\
\hline 2.55 & 1.40 & 2.2838 & 0.0068 & 0.0403 & 0.1674 \\
\hline 2.60 & 1.41 & 2.2412 & 0.0066 & 0.0396 & 0.1667 \\
\hline 2.65 & 1.42 & 2.2002 & 0.0065 & 0.0389 & 0.1661 \\
\hline 2.70 & 1.43 & 2.1608 & 0.0063 & 0.0382 & 0.1655 \\
\hline 2.75 & 1.44 & 2.1228 & 0.0062 & 0.0375 & 0.1649 \\
\hline 2.80 & 1.45 & 2.0862 & 0.0061 & 0.0369 & 0.1643 \\
\hline 2.85 & 1.46 & 2.0509 & 0.0059 & 0.0363 & 0.1637 \\
\hline 2.90 & 1.47 & 2.0169 & 0.0058 & 0.0356 & 0.1631 \\
\hline 2.95 & 1.48 & 1.9840 & 0.0057 & 0.0351 & 0.1625 \\
\hline 3.00 & 1.48 & 1.9522 & 0.0056 & 0.0345 & 0.1620 \\
\hline
\end{tabular}

Table 2 - Comparison of Single Sampling, Double Sampling and ZOSS

\begin{tabular}{|c|c|c|c|c|c|c|c|c|c|c|c|c|c|c|c|c|c|c|c|c|c|}
\hline \multicolumn{5}{|c|}{$\operatorname{QSS-1}\left(n, k_{n}, c_{0}\right)$} & \multicolumn{5}{|c|}{$\operatorname{QSS-2}\left(n, k_{n}, c_{0}\right)$} & \multicolumn{5}{|c|}{$\operatorname{QSS-3}\left(n, k_{n}, c_{0}\right)$} & \multicolumn{4}{|c|}{$\operatorname{ZOSS}(\mathbf{n}, \mathrm{k})$} & \multirow{2}{*}{$\mathbf{E}_{1} *$} & \multirow{2}{*}{$\mathbf{E}_{2} *$} & \multirow{2}{*}{$\mathbf{E}_{3} *$} \\
\hline c & $\mathbf{k}$ & $\mathrm{np}_{0.95}$ & $\mathrm{np}_{0.10}$ & OR & c & $\mathbf{k}$ & $\mathrm{np}_{0.95}$ & $\mathrm{np}_{0.10}$ & OR & c & $\mathbf{k}$ & $\mathrm{np}_{0.95}$ & $\mathrm{np}_{0.10}$ & $\mathbf{O R}$ & $\mathbf{k}$ & $\mathrm{np}_{0.95}$ & $\mathrm{np}_{0.10}$ & OR & & & \\
\hline 1 & 1.25 & 0.35 & 3.12 & 9.01 & 1 & 1.25 & 0.35 & 3.19 & 9.11 & 1 & 1.25 & 0.34 & 3.11 & 9.08 & 1.50 & 0.18 & 1.66 & 9.09 & 1.90 & 1.92 & 1.88 \\
\hline 1 & 1.50 & 0.34 & 2.61 & 7.74 & 1 & 1.50 & 0.35 & 2.74 & 7.91 & 1 & 1.50 & 0.33 & 2.59 & 7.86 & 1.95 & 0.1 & 1.35 & 7.68 & 1.92 & 1.96 & 1.88 \\
\hline 1 & 1.75 & 0.33 & 2.25 & 6.68 & 1 & 7.50 & 0.34 & 2.41 & 6.97 & 1 & 1.75 & 0.32 & 2.23 & 6.99 & 2.50 & 0.17 & 1.12 & 6.64 & 1.95 & 2.02 & 1.89 \\
\hline 1 & 2.00 & 32 & 1.97 & 18 & 1 & 2 & 0.33 & 16 & 6.4 & 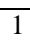 & 2.00 & 0.31 & 1.9 & 6.31 & 2.85 & 0.1 & 1.10 & 6.18 & 1.95 & 2.00 & 1.87 \\
\hline
\end{tabular}

Where

$* \mathrm{E}_{1}=\mathrm{np}_{0.95}$ of QSS-1 $\left(\mathrm{n}, \mathrm{kn}, \mathrm{c}_{0}\right) /{ }_{0.95}$ of ZOSS (n, k)

$* \mathrm{E}_{3}=\mathrm{np}_{0.95}$ of QSS-3(n, kn, $\left.\mathrm{c}_{0}\right) / \mathrm{np}_{0.95}$ of ZOSS (n, k)

$* \mathrm{E}_{2}=\mathrm{np}_{0.95}$ of QSS-2(n, kn, $\left.\mathrm{c}_{0}\right) / \mathrm{np}_{0.95}$ of ZOSS (n, k) and 